Comparative Philosophy Volume 10, No. 1 (2019): 218-221

Open Access / ISSN 2151-6014 / www.comparativephilosophy.org

https://doi.org/10.31979/2151-6014(2019).100116

CONSTRUCTIVE-ENGAGEMENT DIALOGUE (3.2)

\title{
REPLY TO CARLOS MONTEMAYOR \& ABROL FAIRWEATHER
}

\author{
JONARDON GANERI
}

I'm very grateful to Carlos Montemayor and Abrol Fairweather for their penetrating and insightful review of my new book Attention, Not Self. I'm also delighted to learn now of their own new book, Knowledge, Dexterity, and Attention: A Theory of Epistemic Agency, which also came out in 2017. There are many fascinating resonances between our respective projects, and it is well worthwhile to try to understand how they complement and reinforce one another, and where, if at all, we are at odds. I will make a first start on this large task in this reply.

My aim in Attention, Not Self was to reconstruct a reoriented philosophy of mind that has its antecedents in the work of 5th century Buddhist philosophy in Pāli. From a contemporary perspective, this philosophy of mind is extremely intriguing for two reasons.

First, it identifies attention as having foundational explanatory importance, and throughout the book I show how a range of conscious mental phenomena can be understood from what I call an Attentionalist stance. I argue, specifically, that there are attention-based accounts of episodic memory and empathy, and that these can be used to construct a new, apophatic, theory of persons. I also emphasise the close connection between attention and knowledge, arguing that attending is, in the right circumstances, a way of knowing (what other Indian thinkers call a pramāna). I also distinguish between two levels of explanation in the philosophy of mind, a level at which what one deals with are modular cognitive scientific processes, and another level at which one is dealing with conscious mental content, and I distinguish between two corresponding notions of attention (of which only the former, and not the latter, is subject to a functionalist and modular analysis).

Second, this philosophy of mind firmly and unequivocally rejects a particular conception of self. The conception in question is that of a self as an uncaused first cause of actions, the simple origin of willed directives. I call this the "Authorship view" of self. Rejection of this agent-causalist conception is, evidentally, compatible with endorsement of other, less metaphysically loaded, conceptions of self. And,

GANERI, JONARDON: Professor, College of Arts \& Science, New York University, USA. Email: jonardon.ganeri@nyu.edu 
importantly, it is also compatible with allowing there to be agency, and so a distinction between actions that are guided and those that are involuntary. One might summarise the view in the slogan that there is agency but no agents, but one needs to exercise caution in doing so, because what is really at stake is the relative metaphysical priority of agency and agents. My view is perfectly compatible with deflationary and reductionist accounts of agents, but not with the agent-causalist picture of agents. Indeed Part V reconstructs an account of persons qua moral agents from the materials about attention and its derivatives developed in the earlier parts of the book.

The title of my book highlights these two ideas: Attention, Not Self is an abbreviation for "A theory of mind in which attention has explanatory priority and in which no explanatory role is given to the agent-causalist (or authorship view of) picture of agent selves." The philosophy of mind presented here, one which I excavate at least in part from Pāli Buddhist sources without claiming any given Buddhist to have endorsed it, is thus both anti-Cartesian and anti-Kantian, for it rejects both the Cartesian res cogitans and the Kantian pure will. In its metaphysics it is perhaps not radically different from strands in contemporary analytical philosophy of mind, its originality within the contemporary discussion having rather to do with the nature of the explanatory project it embodies.

In their marvellous book, Knowledge, Dexterity, and Attention: A Theory of Epistemic Agency, Carlos Montemayor and Abrol Fairweather defend a particular account of epistemic agency. They advocate what they call "an attentional turn" in epistemology, and set out to demonstrate that our understanding of epistemic agency can be informed by an epistemic psychology grounded in attention. The theory of epistemic agency they defend is one designed to be specifically suited for a virtue reliabilist theory of knowledge. Now my advocacy of an "attentionalist stance" and Montemayor and Fairweather's assertion that there needs to be an "attentional turn" are highly sympathetic to one another. The only difference is that I spend most of my discussion on topics in the philosophy of mind, with a comparartively small discussion of epistemology, while they explore the implication of an attentional turn for epistemology in far greater detail.

What about our respective treatments of epistemic agency? In their book, Montemayor and Fairweather summarise the view they are defending as follows: "We argue that virtue reliabilism will prosper by incorporating the account of epistemic agency defended here. We will show how sufficient agent-level credit is due to an agent for manifesting a reliable cognitive constitution, and this in turn is understood as an integrated set of attentional (and thus agential) cognitive dispositions. Importantly, we argue that, with an attentional turn, even basic epistemic achievements like reliable perception or the deliverances of a capacious memory will be agential, and will thus underwrite the distinctive value virtue epistemologists associate with achievements that manifest agency" (p.3). The importance of the stress on integration is that it replaces second-order accounts of agency such as that of Ernest Sosa. Montemayor and Fairweather say that an emphasis on second-order states "seems to miss the most essential feature of mental action, namely integration. 
Two states or processes can be cognitively integrated without one of them being about the other...there are relations of influence and control between them, but not meta-representation" (p.101). The central idea, then, is that virtue epistemology has associated itself with the wrong sort of model of an epistemic agent and that it does better to reject that model in favour of another one.

In Attention, Not Self I make a series of precisely parallel claims about the relationships between agency and attention. I argue in Chapter 14 that the secondorder theory (which I there associate with the views of Harry Frankfurt) should be discarded in preference for a first-order theory, and in Chapter 11 I claim that the notion of intending is that of a specific sort of integration, associated with the role Buddhists give to their notion of cetan $\bar{a}$, a control factor within conscious thought. In addition, in my discussion of perception in Chapters 4 and 5, and memory in Chapter 12 , I argue that the sort of agency these achievements embody is derived from the agency intrinsic to acts of attention, having already argued in Chapter 1 that attention is a sort of mental action. The point of that discussion was to emphasises that there is no controller outside the controlled and controlling activities of attention.

In their review, Montemayor and Fairweather worry that my denial of the agentcausalist model of agency is incompatible with the virtue theoretic approach, on the grounds that "virtue epistemology is considered an 'agent based' perspective in epistemology because of the widely shared view that a true belief must manifest the cognitive abilities of the agent to count as knowledge". Yet they soon note, and I agree, that the incompatibility disappears if virtue theorists abandon commitment to agent-causalism in favour of the sort of integrationist first-order theory they themselves advocate, in which case "current theorizing about epistemic agency might benefit hansomely by heeding suggestions from the psychology of attention, in which case the attentional turn Ganeri defends is not only compatible with the agential turn in epistemology, but may be a powerful ally going forward".

Montemayor and Fairweather speak in their review of a minimal notion of a causally efficacious agent. Summarising their book, they say that they "understand the success of the minimal agent in terms of cognitive dispositions that reliably manifest attention's insensitivity to defeaters and distractors and the internal normative force of attentional anchoring through cognitive constitution and control". They go on to "propose that Ganeri's account of knowledge and justification based on attention capacities is best understood in terms of...the presumption of a minimal epistemic agent". I agree and find no difficulty in accepting this notion of a minimal agent (not, of course, to be confused with Dan Zahavi's notion of a minimal self, which is that of an immersed subject of experience, but rather the apophatic conception of persons as set out on pp. 299-304). For in my discussion of the two roles of attention, in Chapter 5, I stress that attention serves the twin roles of anchoring onto a target and eliminating distractors, and indeed take that to be the reason attentional actions are subject to epistemic norms.

What I do in my book is to avoid putting matters in terms of the manifestation of cognitive abilities and dispositions, because that already (and in my view unnecessarily) imports a substantival metaphysics according to which agency is the 
manifestation of an ability possessed by an independently existing agent. Rather the underlying metaphysics is trope-theoretic, and it is an appropriate integration of conceptual and cognitive tropes which constitutes the minimal agent. My view is thus that the attentional turn in epistemology and the philosophy of mind requires a corresponding anti-Aristotelian turn in metaphysics. In this I think Montemayor and Fairweather agree, stressing that while it has traditionally been the case that virtue theory has associated itself with an Aristotelian metaphysical framework, if they are right it better executed with commitment only to minimal agents.

\section{REFERENCES}

Montemayor, Carlos \& Fairweather, Abrol (2019), "Review of Attention Not Self by Jonardon Ganeri", Comparative Philosophy 10.1: 155-160.

Zahavi, Dan (2015), Self and Other (Oxford: Oxford University Press). 